Research Paper

\title{
Antarctica Plate Motion
}

\author{
SAPNA GHAVRI $^{1}$, JOSHI K CATHERINE ${ }^{1}$, A AMBIKAPATHY ${ }^{2}$, AMIT KUMAR ${ }^{1}$ and VINEET K \\ GAHALAUT ${ }^{2, *}$ \\ ${ }^{1}$ CSIR-National Geophysical Research Institute, Hyderabad 500 007, India \\ ${ }^{2}$ National Centre for Seismology, Ministry of Earth Sciences, New Delhi 110 003, India
}

(Received on 22 June 2016; Accepted on 23 November 2016)

\begin{abstract}
We have analysed GPS measurements of site motion from fifty sites in the Antarctica, including the one set up by us at Maitri. The Maitri site exhibits a predominantly northward velocity of $\sim 8 \mathrm{~mm} /$ year. Elsewhere on the Antarctica plate the site velocity estimates vary from 4 to $20 \mathrm{~mm} /$ year and exhibit spectacular rotation of the atlantic plate. The estimated pole of the Antarctica plate is located on the plate itself and thus the plate, surrounded by mostly the divergent plate margins, appear to spin along this pole. Large seasonal variations are seen in displacement time series from sites which are located closer to the pole.
\end{abstract}

Keywords: Antarctica; Maitri; Plate Motion; GPS Measurements

\section{Introduction}

The Antarctica, which is the fifth largest of the seven continents on Earth, was the part of the supercontinent Gondwana more than 170 million years ago. Over time Gondwana broke apart and Antarctica was formed around 35 million years ago. The area of Antarctic plate is 61 million $\mathrm{km}^{2}$, which is almost five times that of the Indian plate. The Antarctic plate has a unique geodynamic setting since it is almost completely ( $87 \%$ ) surrounded by mid-oceanic ridges, divergent or conservative margins which are formed due to interaction of the Antarctic plate with the South America plate, Africa plate, Australia plate, Pacific plate and Nazca plate (Fig. 1). Only a small part of it abuts the subduction zone, which is formed due to interaction of the South America plate, Scotia plate and Antarctic plate. Seismicity in the Antarctica plate interiors is generally low. Most of the seismicity is concentrated on the plate boundary. A few earthquakes occur in the volcanic region in the western Antarctica and peninsular region (Reading, 2007). The continental interior shows suppression of crustal failure due to ice loading causing low seismicity. Ice quakes occur in the continental shelf region due to ice shelf breakoff.
CSIR-National Geophysical Research Institute (NGRI) with the support from ESSO-National Centre for Antarctic and Ocean Research (NCAOR) established a permanent GPS station in the year 1997 at the Indian base station Maitri. Majority of data from this site were acquired in campaign mode. However, over the years, the site became unstable. The results from this site have been reported earlier (Ghavri et $a l ., 2015)$. A new station MAIT was established at Maitri in 2013 (Fig. 2). In this article, we report on the Antarctic plate motion through GPS measurements. A few attempts have been made earlier (Argus et al., 2014; Bouin and Vigny, 2000; Dietrich et al., 2004; Donnellan and Luyendyk 2004), however, the number of GPS sites used to estimate the plate motion in these studies were small. Our study involving data from 48 sites provides the most comprehensive analysis so far.

\section{GPS Measurements and Analysis}

We analysed the data from Maitri station (MAIT) along with forty seven other GPS stations from UNAVCO (University NAVSTAR Consortium) and SOPAC (Scripps Orbit and Permanent Array Center). We used GAMIT-GLOBK software (Herring et al., 

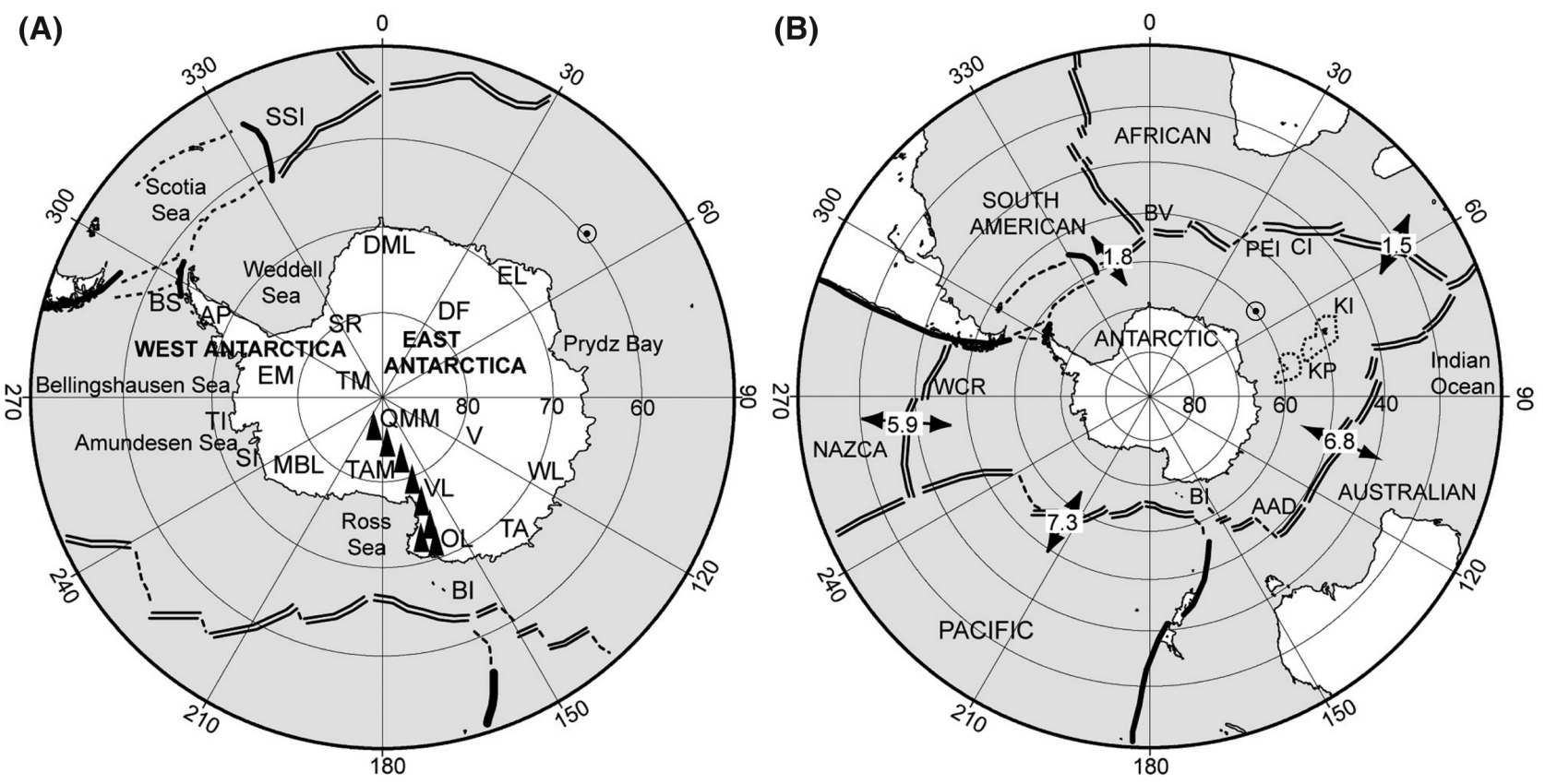

Fig. 1: (A) Geographical Locations and major physiographic features of Antarctica. SSI-South Sandwich Islands, BS-Bransfield Strait, AP-Antarctic Peninsula, TI-Thurston Island, SI-Siple Island, MBL-Marie Byrd Land, TAM-Transantarctic Mountains, VL-Victoria Land, OL-OatesLand, V-Vostok, Lake Vostok, TA-Terre Adelie, WL-Wilkes Land, EL-Enderby Land, DF-DomeFuji, DML-Dronning Maud Land, SR-Shackleton Range, TM-Thiel Mountains, EM-Ellsworth Mountains; (B) The Antarctic Plate and surrounding Plates. BV-Bouvet Triple Junction, WCR-West Chile Rise, BI-Balleny Islands, AAD-Australian-Antarctic Discordance, KP-Kerguelen Plateau, KI-Kerguelen Islands, CI-Crozet Islands, PEI-Prince Edward Islands. Numbers indicate divergence rates in $\mathrm{cm} / \mathrm{year}$. Plate margins are: divergent-double line, convergentsingle thick line, other-dotted line. The dot and circle in each panel represents the anti-pole of the Antarctica plate, estimated in this study. Modified after Reading (2007)

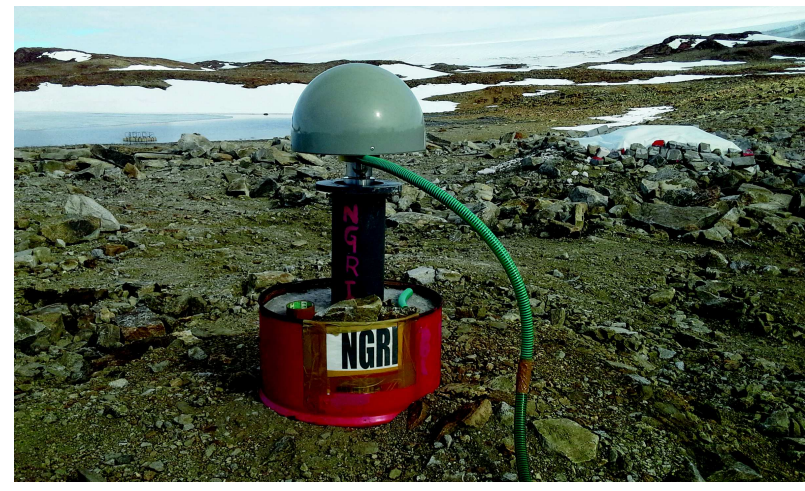

Fig. 2: GPS site at Maitri, Antarctica, established in 2013

2010a, b; King and Bock, 2006) to process GPS data in ITRF08 reference frame. The estimated velocity is less about $4 \mathrm{~mm} / \mathrm{yr}$ in the eastern part of East Antarctica and about $20 \mathrm{~mm} / \mathrm{yr}$ in the western part of West Antarctica and Antarctic Peninsula. We observed that the Antarctic Plate is moving towards the South American Plate (Fig. 3). The estimated velocity at Maitri is predominantly towards north with a rate of $8 \pm 1 \mathrm{~mm} / \mathrm{yr}$.
We found that the site motion in Antarctica is spectacular in the sense that the plate appears to rotate. Such a motion is not observed for any other plate on the globe. We use the site motion data to estimate the Euler pole of rotation. The Euler Pole, estimated by considering Antarctic Plate as a single plate is at $58.69 \pm 0.41^{\circ} \mathrm{N}$ latitude, $130.18 \pm 0.41^{\circ} \mathrm{W}$ longitude and is rotating with an angular velocity of $0.2153 \pm 0.0021 \%$ myr. Such a pole will cause rapid variations in the plate velocity, which is evident from that estimated from GPS measurements. As discussed earlier, that the Antarctica plate is mainly surrounded by the mid-oceanic ridges, the convergent plate margins, and only a small part of it joins the subduction zone, south of South America plate. On the other hand, majority of the other plates are surrounded by both divergent as well as convergent plate margins and hence those plates move largely in one direction. However, unique plate margin boundaries setting of the Antarctica plate causes a spinning type of motion of this plate. 


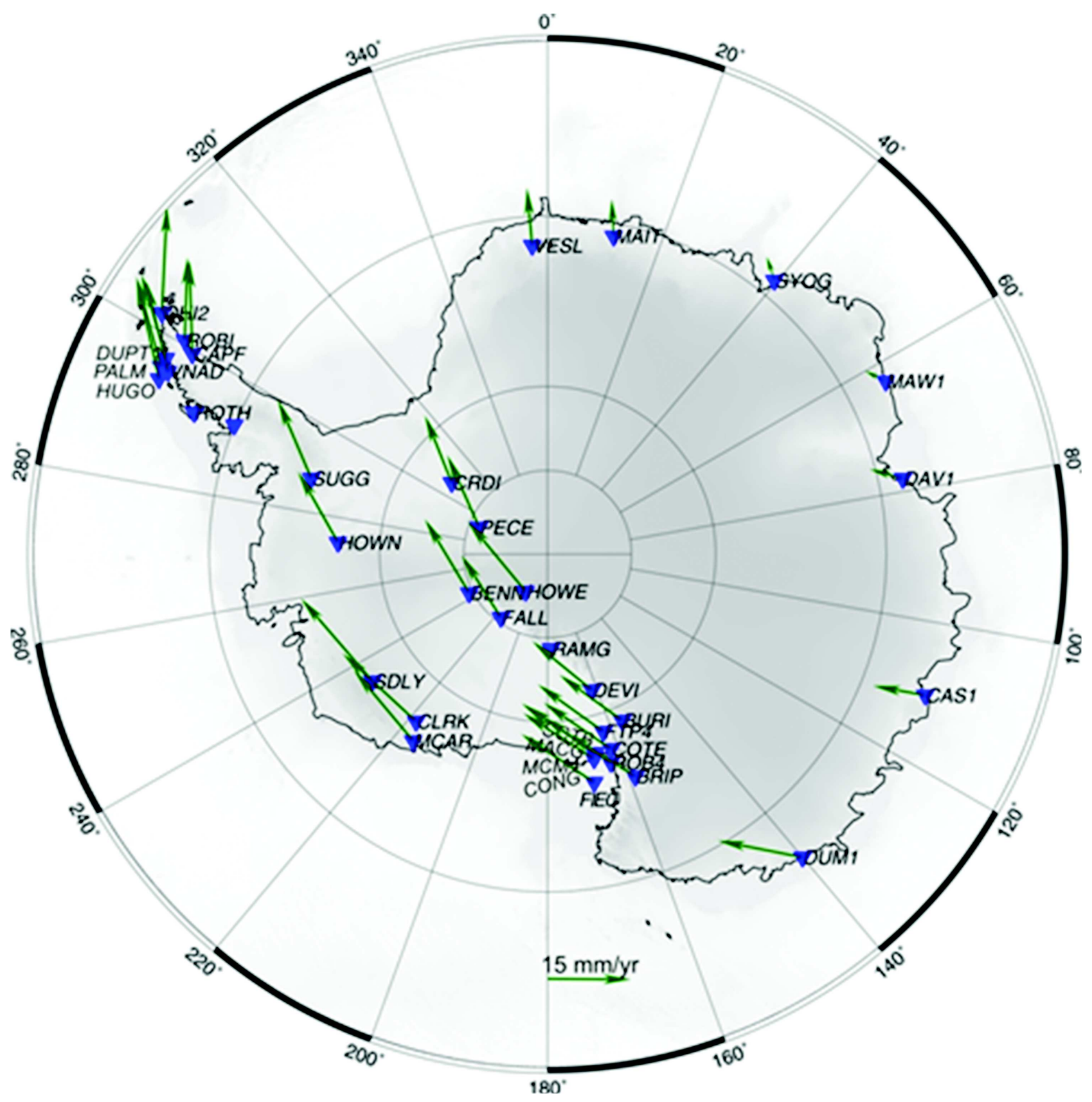

Fig. 3: ITRF08 velocity for the 48 sites on the Antarcticacontinent. Indian GPS site at Maitri is shown as MAIT

\section{Seasonal Variations in the Plate Motion and Internal Deformation of the Plate}

There is large velocity variations at sites in the Antarctica plate. The systematic large variations in the site velocity are primarily due to the fact that the Euler antipole of the plate is located on the plate itself. The volcanic province in the western Antarctica also causes some variations in the site motion. In the peninsular Antarctica, the variations in the site motion is primarily due to the proximity of the suduction zone. There is also possibility of some internal deformation, as evident from the presence of high topographic feature, the Trans-Antarctic mountains. Such deformation is very small, less than a couple of $\mathrm{mm} /$ year. Quantifying of such deformation by using longer time series data has been taken up. Low internal deformation in the Antarctica is consistent with the general absence of earthquakes in the Antarctica plate region. 
Besides variations in the site motion, there are seasonal variations at some sites. Seasonal variations, daily as well as annual, in Antarctica are mainly because of the fact that it is a polar region. Daily and annual variations in the equatorial regions of Antarctica (away from pole) probably occur due to change in temperature, total electron content during and day and night condition, humidity, pressure, and precipitation. At sites in the Antarctica polar region, such changes are more prominent and are annual and show variations in the horizontal motion up to $\sim 3 \mathrm{~cm}$ and in vertical as much as $\sim 5 \mathrm{~cm}$. To understand these changes, modelling the effect of each sources is being contemplated.

\section{Conclusions}

We analyse GPS measurements in the Antarctica region to constrain its motion. Our site at Maitri shows a predominantly northward motion of $\sim 8 \mathrm{~mm}$ /year. The motion of the plate is predominantly towards South American plate and it appears to be spinning. Such a spinning motion is primarily due to the fact that is it is surrounded by the divergent or conservative plate boundaries. This is also consistent with the derived pole of rotation for this plate, which is located on the Antarctica plate itself. There are large seasonal variations in the motion which may be mainly due to the polar conditions.

\section{Acknowledgements}

We thank Dr. Shailesh Nayak for inviting us to write this article and an anonymous reviewer for his constructive comments. ESSO-NCAOR support in establishing seismological and GPS site is greatly appreciated.

\section{References}

Argus D F, Peltier W R, Drummond R and Moore A W (2014) The Antarctica component of postglacial rebound model ICE-6G_C (VM5a) based on GPS positioning, exposure age dating of ice thicknesses, and relative sea level histories Geophysical Journal International 198 537-563

Bouin M N and Vigny C (2000) New constraints on Antarctic plate motion and deformation from GPS data Journal of Geophysical Research: Solid Earth (1978-2012) 105 28279-28293

Dietrich R, Rülke A, Ihde J, Lindner K, Millerd H, Niemeiere W, Schenkef H.-W and Seeber G (2004) Plate kinematics and deformation status of the Antarctic Peninsula based on GPS Global and Planetary Change 42 313-321 doi: 10.1016/j.gloplacha.2003.12.003

Donnellan A and Luyendyk B P (2004) GPS evidence for a coherent Antarctic plate and for postglacial rebound in Marie Byrd Land Global and Planetary Change 42 305311

Ghavri S, Catherine J K and Gahalaut V K (2015) First estimate of plate motion at Maitri GPS site, Indian Base station at Antarctica Journal Geological Society of India 85 431-433

Herring T A, King R W and McClusky S C (2010a) Documentation of the GAMIT GPS Analysis Software release 10.4. Department of Earth, and Planetary Sciences. Massachusetts Institute of Technology, Cambridge

Herring T A, King R W and McClusky S C (2010b) GLOBK, Global Kalman filter VLBI and GPS analysis program, version 10.4. Department of Earth, and Planetary Sciences, Massachusetts Institute of Technology, Cambridge

King R W and Bock Y (2006) Documentation of the GAMIT GPS analysis software. Massachusetts Institute of Technology, Massachusetts

Reading A M (2007) The seismicity of the Antarctic plate, In Stein $S$ and Mazzotti $S$ ed, Continental Intraplate Earthquakes: Science, Hazard, and Policy Issues Geological Society of America Special Paper 425 285-298 doi: 10.1130/ 2007.2425(18). 